\title{
Impatiens morsei Ноок. f. (Balsaminaceae) - eine außer Mode geratene Zierpflanze in botanischen Gärten
}

\author{
Josef BOGNeR
}

\begin{abstract}
Impatiens morse $i$ was introduced in the trade as an ornamental plant, but has disappeared there in the meantime. This nice species is still cultivated in botanical gardens. Its origin is discussed and a description of this plant is given.
\end{abstract}

\section{Zusammenfassung}

Impatiens morsei wurde in den Handel als Zierpflanze eingeführt, ist dort aber inzwischen wieder verschwunden. Diese schöne Art befindet sich heute noch in botanischen Gärten in Kultur. Ihre Herkunft wird besprochen und eine Beschreibung dieser Pflanze gegeben.

\section{Von Vietnam über Russland nach Deutschland}

In den neunziger Jahren des vorigen Jahrhunderts wurde eine interessante Impatiens-Art in den Handel eingeführt und als Sorte unter dem Namen Impatiens 'Velvetia' (oder auch 'Velvetea', in England noch unter dem Sortennamen 'Secret Love') bezeichnet, was sich auf den samtigen Glanz der Blätter bezieht. In einem kurzen Artikel von RüCKer (1997) ist zu lesen, dass diese Art im Dschungel Westafrikas entdeckt wurde, was allerdings nicht stimmt. Tatsächlich handelt es sich um eine Wildart aus Vietnam und nicht um eine Kultursorte. Im Jahre 1996 hat der russische Botaniker Nicolaj Arnautov lebende Pflanzen dieser Art in der Provinz Ninh Binh im Nationalpark Cuc Phuong nahe der Höhle prähistorischer Menschen gesammelt und an den Botanischen Garten des KomarovInstitutes in St. Petersburg gesandt. Von dort sind lebende Pflanzen nach Deutschland gelangt und wurden hier weiter kultiviert. Sie kamen dann durch eine niederländische Gärtnerei als eine neue Topfpflanze in den Handel, sind aber heute wieder verschwunden. Allerdings sind von dieser schönen Art noch Pflanzen in botanischen Gärten, so z. B. im Botanischen Garten München, in Kultur. Impatiens morsei ist in Hooker's Icones Plantarum (1908) vor fast einhundert Jahren beschrieben.

Impatiens morsei ist in Südchina und Nordvietnam verbreitet und kommt in China in der

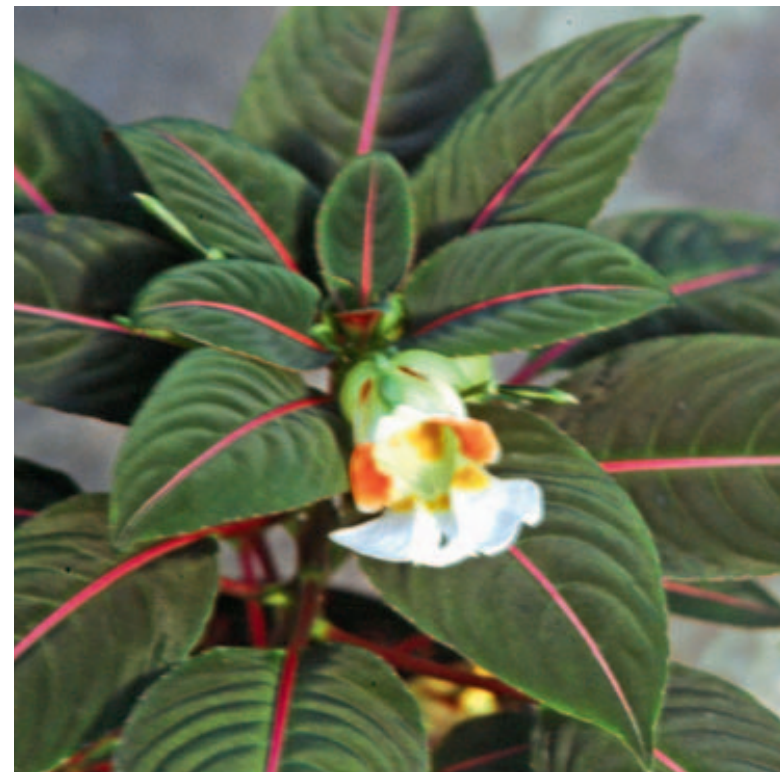

\section{Beschreibung von Impatiens morsei}

Pflanze ausdauernd, bis $40 \mathrm{~cm}$ hoch, kahl, Spross aufrecht, an der Basis bis $1 \mathrm{~cm}$ im Durchmesser, verzweigt, Internodien 1 bis $1,5 \mathrm{~cm}$ lang. Blätter wechselständig, zur Spitze hin dichter stehend; Blattstiel 3 bis $6 \mathrm{~cm}$ lang und 0,2-0,3 cm im Durchmesser, weinrot bis purpurfarben; Blattspreite eiförmig bis elliptisch, 7-10 (13) cm lang und 3-5 (7) $\mathrm{cm}$ breit, dunkelgrün und mit hellrotem Mittelnerv auf der Oberseite und samtig glänzend, auf der Unterseite weinrot bis purpurfarben, an der Basis keilförmig und am Ende zu- 
gespitzt, Blattrand gekerbt und mit kleinen Zähnchen versehen, an der Basis der Blattspreite mit zwei rundlichen Drüsen (deutlich sichtbar auf der Unterseite); beiderseits des Mittelnervs 6-10 Seitennerven, meist etwas undeutlich sichtbar. Blüten meist einzeln in den Blattachseln der oberen Blätter und gerade diese überragend. Blütenstiel 3,5-5 cm lang und ca. 1,5 mm im Durchmesser, meist grünlich oder rötlich, dünn, verlängert sich zur Fruchtreife. Blüte ca. $3 \mathrm{~cm}$ im Durchmesser; Kelchblätter ungleich groß; die beiden seitlichen Kelchblätter ca. 1,5 cm lang und $1 \mathrm{~cm}$ breit, hellgrün und unregelmäßig fein rötlich gepunktet, dazwischen zwei kleine, 2-3 mm lange, schuppenförmige und grünliche Kelchblätter; unteres Kelchblatt größer, annähernd halbkugelig geformt, ca. 1,5 cm im Durchmesser, grünlichweiß bis weiß und innen mit zinnoberroten bis hellroten Flecken besetzt sowie mit einem rechtwinkelig gebogenen, 0,7-0,9 cm langen, grünlichweißen, auf Dreiviertel seiner Länge zweigeteilten Sporn versehen; dorsales Kronblatt ca. 1,5 cm lang und ca. $1 \mathrm{~cm}$ breit, mehr oder weniger kahnförmig, in der Mitte etwas gekielt und grün, sowie weißlich zu den Rändern hin, an der Spitze innen mit ein paar rötlichen Flecken; die seitlichen, verwachsenen Kronblätter (Flügel) $2,5-3 \mathrm{~cm}$ lang, weiß, die seitlichen, zurückgebogenen Ränder zinnoberrot bis hellrot, vorderer Teil (Lippe) ca. 1,5 cm lang, zweilappig (in der Mitte tief eingeschnitten), reinweiß und am Eingang zur Blüte goldgelb gezeichnet, jeder Lappen mit einem deutlichen Kiel; die verwachsenen Kronblätter bilden einen runden Eingang zur Blüte; Staubgefäße 5, Staubfäden verwachsen, Antheren cremefarben; Fruchtknoten spindelförmig, grün; Narbe sehr klein. 
ler dieser Art, H. B. Morse (1855-1934), benannt, der mehrere Jahre in China lebte und dort unter anderem auch Pflanzen sammelte. Seine Sammlungen sowie Notizen und Zeichnungen wurden später dem Kew-Herbarium übergeben, wo sie bis heute aufbewahrt werden.

\section{Kultur}

Die Kultur erfolgt im temperierten Gewächshaus oder Warmhaus; im Winter sollte die Temperatur nicht unter $16^{\circ} \mathrm{C}$ fallen. Als Substrat ist eine humose Erde zu verwenden und die Pflanze sollte wenigstens einen halbschattigen Standort haben. Ansonsten stellt Impatiens morsei keine besonderen Ansprüche, scheint aber über die Wintermonate etwas empfindlich zu sein. Die Vermehrung erfolgt am besten im Frühjahr und Sommer durch Stecklinge, die sich leicht bewurzeln lassen. Diese Art zeichnet sich durch eine lange Blütezeit aus, was auch für viele andere Vertreter der Gattung Impatiens zutrifft. Es ist eigentlich sehr schade, dass der Handel sich für diese Art nicht mehr interessiert. Es bleibt zu hoffen, dass sie in Zukunft wenigstens in einigen botanischen Gärten den Besucherinnen und Besuchern gezeigt werden kann.

\section{Dank}

Ich danke Herrn Dr. T. Shimizu, Matsumoto (Japan) für die Bestimmung dieser Art und Herrn M. Umebayashi von der Universität Kanazawa (Japan) für die hervorragende Zeichnung.

\section{Literatur}

Grey-Wilson, C. 2005: Impatiens morsei. - In: Curtis' Botanical Magazine, New Series, vol. 22: 152, T. 530 Kew.

Hooker, J. D. 1908: Impatiens morsei Hook. f. - In: Hooker's Icones Plantarum 9: T. 2874.

RÜCKer, K. 1997: Neue attraktive Topfpflanze. Gartenpraxis 23: 5.

Abb. 4 (oben): Blüte der Impatiens morsei von vorne.

Abb. 5 (unten): Impatiens morsei. A Blatt von der Unterseite; B Basis der Blattspreite mit den beiden Drüsen; C Blüte in seitlicher Ansicht; D Blüte von oben gesehen; E seitliches Kelchblatt; F kleines, schuppenförmiges Kelchblatt; G unteres Kelchblatt mit Sporn und Staubgefäßen, in seitlicher Ansicht; $\mathrm{H}$ unteres Kelchblatt von hinten gesehen, mit Sporn.
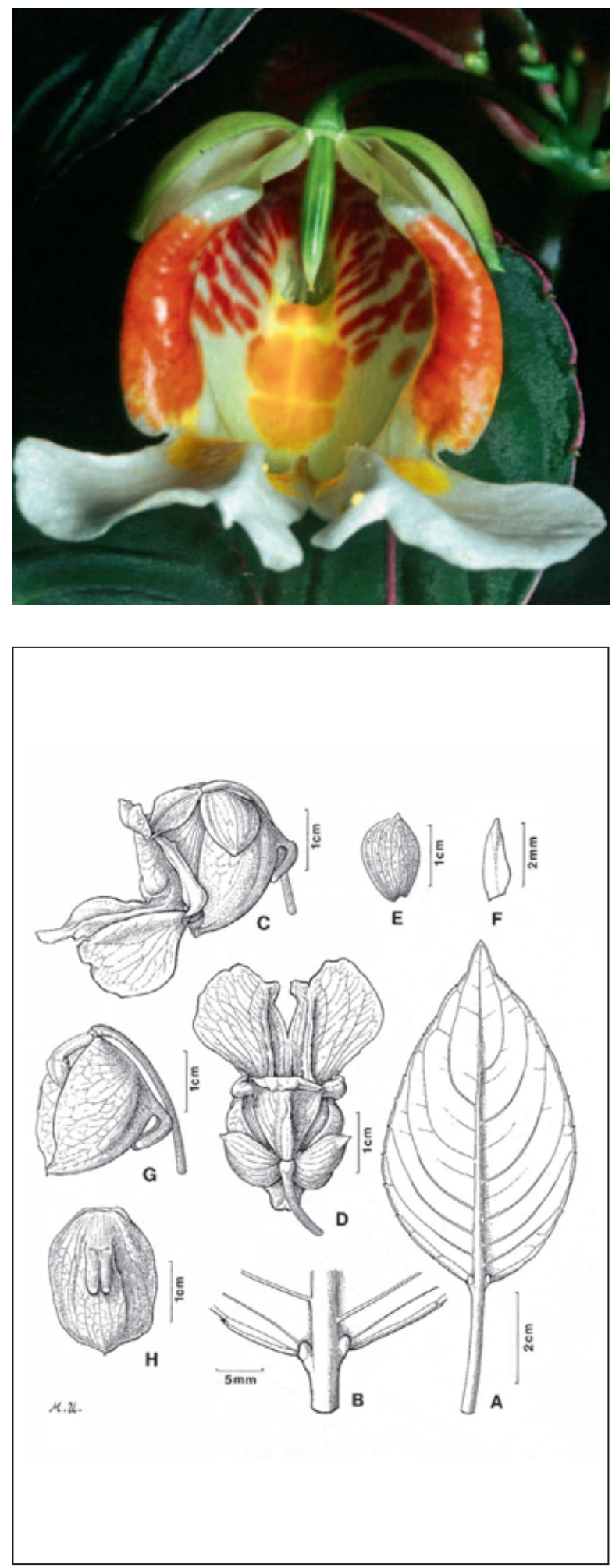